\title{
In vitro evaluation of the cytotoxic and trypanocidal activities of Ampelozizyphus amazonicus (Rhamnaceae)
}

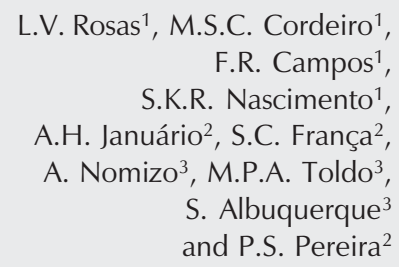

\author{
1Departamento de Química, Universidade do Amazonas, Manaus, AM, Brasil \\ ${ }^{2}$ Unidade de Biotecnologia Vegetal, Universidade de Ribeirão Preto, \\ Ribeirão Preto, SP, Brasil \\ ${ }^{3}$ Departamento de Análises Clínicas, Toxicológicas e Bromatológicas, \\ Faculdade de Ciências Farmacêuticas, Universidade de São Paulo, \\ Ribeirão Preto, SP, Brasil
}

\section{Correspondence}

P.S. Pereira

Unidade de Biotecnologia, UNAERP

Av. Costábile Romano, 2201

14096-900 Ribeirão Preto, SP Brasil

Fax: +55-16-3603-7030

E-mail: ppereira@unaerp.br

Research supported by the Universidade Federal do Amazonas (UFAM) and Universidade de Ribeirão Preto (UNAERP). L.V. Rosas was the recipient of a CAPES scholarship.

Publication supported by FAPESP. $\ldots \ldots \ldots$

Received April 11, 2006 Accepted February 21, 2007 .............................

\begin{abstract}
Ampelozizyphus amazonicus Ducke is a tree commonly found in the Amazon region and an extract of its stem bark is popularly used as an antimalarial and anti-inflammatory agent and as an antidote to snake venom. Ursolic acid; five lupane type triterpenes: betulin, betulinic acid, lupenone, 3ß-hydroxylup-20(29)-ene-27,28-dioic acid, and $2 \alpha, 3 \beta$-dihydroxylup-20(29)-ene-27,28-dioic acid, and three phytosteroids: stigmasterol, sitosterol and campesterol, have been isolated from stem extracts of A. amazonicus Ducke. Their structures were characterized by spectral data including COSY and HMQC. In an in vitro biological screening of the isolated compounds, 3ß-hydroxylup20(29)-ene-27,28-dioic acid was cytotoxic against the SKBR-3 human adenocarcinoma cell line ( 1 to $10 \mathrm{mg} / \mathrm{mL}$ ), while $2 \alpha, 3 \beta$ dihydroxylup-20(29)-ene-27,28-dioic acid exhibited cytotoxicity against both SKBR-3 human adenocarcinoma and C-8161 human melanoma tumor cell lines $(>0.1 \mathrm{mg} / \mathrm{mL})$. In the present study, different extracts and some fractions of this plant were also investigated for trypanocidal activity due to the presence of pentacyclic triterpenes. The triterpene classes are potent against Trypanosoma cruzi. The bioassays were carried out using blood collected from Swiss albino mice by cardiac puncture during the parasitemic peak (7th day) after infection with the Y strain of $T$. cruzi. The results obtained showed that A. amazonicus is a potential source of bioactive compounds since its extracts and fractions isolated from it exhibited in vitro parasite lysis against trypomastigote forms of $T$. cruzi at concentrations $>100 \mu \mathrm{g} / \mathrm{mL}$. Fractions containing mainly betulin, lupenone, $3 \beta$-hydroxylup-20(29)-ene-27,28-dioic acid, and $2 \alpha, 3 \beta$-dihydroxylup20(29)-ene-27,28-dioic acid showed more activity than crude extracts.
\end{abstract}

Key words

- Ampelozizyphus amazonicus

- Rhamnaceae

- Pentacyclic triterpenes

- Cytotoxic activity

- Trypanocidal activity 


\section{Introduction}

Ampelozizyphus amazonicus Ducke (Rhamnaceae) is a native tree of the Amazon forest that is popularly known in Brazil as saracura-mirá or cerveja de índio. Infusions of $A$. amazonicus roots are commonly used in traditional medicine as anti-inflammatory preparations, as an antidote to snake venoms and for the treatment and prevention of malaria $(1,2)$. Earlier chemical investigations have reported the presence of saponins in $A$. amazonicus (1,3). Additionally, Rhamnaceae species have shown an inhibitory effect on alcohol-induced muscle relaxation and cytotoxic, genotoxic, neurotoxic, anti-inflammatory, antipyretic, and hepatoprotective activities have been associated with its extracts and pure compounds (4-8).

The transmission of Chagas' disease has become a major health problem in South and Central America, with the transfusion of infected blood being the most significant transmission mechanism (9). The lack of effective medicines against acute and chronic diseases justifies the search for more efficient and less toxic drugs than those currently used. At present, the only trypanocidal compound used to prevent infection in blood banks is gentian violet, but due to its toxic effects and the alarming color acquired by the skin and urine of transfusion recipients, its use is limited (10). Since most of the synthetic compounds used thus far to treat parasitic diseases produce toxic side effects, the nitroheterocycles nifurtimox and benzimidazole used to be the only drugs prescribed in the early stages of trypanosomiasis in America $(11,12)$, but more recently nifurtimox has been banned from the market. For this reason, a continuous search for bioactive trypanocidal compounds, in combination with studies on their mechanism of action to validate the rational development of lead compounds, has motivated the screening of natural products active against Trypanosoma cruzi and related organisms.
In the present study, we report the isolation and structural elucidation of constituents of extracts from A. amazonicus stems collected in Manaus, AM, Brazil. The EtOAc extract and its fractions inhibited the growth of two tumor cell lines and showed potential in vitro lysis of $A$. amazonicus extracts and fractions against trypomastigote forms of $T$. cruzi.

\section{Material and Methods}

Ampelozizyphus amazonicus stems were collected in the Ducke Reserve (Manaus, AM, Brazil). A voucher specimen was identified by Mad de Souza INPA, AM, Brazil) and deposited in the herbarium of the Instituto Nacional de Pesquisa da Amazônia, INPA, under code number 189,858 . The bioassay procedures adopted were approved by the Ethics Committee of Faculdade de Ciências Farmacêuticas, Universidade de São Paulo, which follows the rules recommended by International Guiding Principles for Biochemical Research Involving Animals (CIOMS), Geneva, 1985.

General ${ }^{1} \mathrm{H}$ and ${ }^{13} \mathrm{C}$ NMR spectra were recorded in pyridine- $d_{5}$ at 300 and $75 \mathrm{MHz}$ (Brucker DPX-300, Departamento de Química, FFCLRP, USP, Ribeirão Preto, SP, Brazil), respectively, using tetramethylsilane as internal standard. ${ }^{13} \mathrm{C}$ NMR chemical resonances were qualified for multiplicity by the DEPT sequence. Thin layer chromatography (TLC) precoated plates with silica gel $\mathrm{PF}_{254}$ (Aldrich $^{\circledR}$, Milwaukee, WI, USA) using the following solvent systems: hexane:EtOAc (7:3), $\mathrm{CHCl}_{3}: \mathrm{MeOH}(4: 1)$ and n-butanol:acetic acid:water, 4:1:5, upper phase. TLC color reagent: vanillinsulfuric acid followed by heating. CC: silica gel (230-400 mesh; Merck, Darmstadt, Hessen, Germany). Preparative thin layer chromatography (PTLC) precoated plates with silica gel $\mathrm{G}(1.0 \mathrm{~mm})$ using solvent system $\mathrm{CHCl}_{3}: \mathrm{MeOH}$ (95:5). HPLC was performed under isocratic conditions 
(MeOH: $\mathrm{H}_{2} \mathrm{O}, 4: 1$, v/v) using a diode array detector (Shimadzu, Kyoto, Japan) and a Supelcosil ${ }^{\mathrm{TM}} \mathrm{LC}-18$ column $(10 \times 250 \mathrm{~mm}$, $5 \mu \mathrm{m})$ and a flow rate of $3.0 \mathrm{~mL} / \mathrm{min}$.

\section{Extraction and isolation}

Air-dried and powdered plant material $(900 \mathrm{~g})$ was macerated and successively extracted $(1: 2 \mathrm{~kg} / \mathrm{L}$ ) with organic solvents (hexane, EtOAc, EtOH, and $\mathrm{MeOH}$ ) and water at room temperature for each 7 days. Next, the material was filtered, the solvent evaporated, water was added and the sample was lyophilized. Crude extracts were concentrated to yield hexane $\left(\mathrm{E}_{1}, 1.74 \mathrm{~g}\right), \mathrm{EtOAc}\left(\mathrm{E}_{2}\right.$, $17.33 \mathrm{~g}), \mathrm{EtOH}\left(\mathrm{E}_{3}, 42.09 \mathrm{~g}\right), \mathrm{MeOH}\left(\mathrm{E}_{4}\right.$, $11.02 \mathrm{~g})$, and aqueous $\left(\mathrm{E}_{5}, 1.83 \mathrm{~g}\right)$ extracts. A second extract was obtained by maceration of $2500 \mathrm{~g}$ air-dried and powdered $A$. amazonicus stems in $5 \mathrm{~L}$ methanol. This $\mathrm{MeOH}$ extract $\left(\mathrm{E}_{6}, 50 \mathrm{~g}\right)$ was concentrated under vacuum and submitted to partition with $n$-butanol $\left(\mathrm{E}_{7}, 45.23 \mathrm{~g}\right)$. The insoluble fraction was separated and dried $\left(\mathrm{E}_{10}, 3.84\right.$ g).

Extract $E_{2}$ and fraction $E_{7}$ were submitted to successive steps of column chromatography (silica gel) eluted with a step gradient of hexane, EtOAc and/or chloroform and methanol. Fractions $\mathrm{E}_{2} \mathrm{P}(10.63 \mathrm{~g}), \mathrm{E}_{2} \mathrm{P}_{3}(0.97$ $\mathrm{g}), \mathrm{E}_{2} \mathrm{P}_{9}(0.17 \mathrm{~g})$, and $\mathrm{E}_{7(5 / 6)}(5.78 \mathrm{~g})$ were obtained as above. PTLC and HPLC were used for purification. Fractions were collected and monitored by TLC. Compounds $2(38.6 \mathrm{mg}), 5(95.1 \mathrm{mg})$ and $6(23.9 \mathrm{mg})$ were obtained from the $\mathrm{E}_{2}$ extract and compounds $1(18.1 \mathrm{mg}), 3(4.5 \mathrm{mg})$ and $4(36.5$ $\mathrm{mg}$ ) from the $E_{7}$ fraction. The $E_{3}$ extract $(15.0 \mathrm{~g})$ was submitted to partition with $n$ butanol (EEBAa, $4.15 \mathrm{~g}$ ).

The stem bark aqueous extract was prepared with $1000 \mathrm{~g}$ air-dried stem bark in $2 \mathrm{~L}$ water under mechanical shaking and the extracts with no froth $\left(\mathrm{E}_{8}\right)$ and with froth $\left(\mathrm{E}_{9}\right)$ were separated and lyophilized, yielding 12.27 and $16.65 \mathrm{~g}$, respectively.

\section{Tumor cell line culture}

The SKBR-3 human breast adenocarcinoma and C-8161 human melanoma tumor cell lines were obtained from the American Type Culture Collection (ATCC, Rockville, MD, USA). The tumor cell lines were cultured and maintained in RPMI 1640 medium supplemented with $2 \mathrm{mM}$ L-glutamine, 1.5 $\mathrm{g} / \mathrm{L}$ sodium bicarbonate, $4.5 \mathrm{~g} / \mathrm{L}$ glucose, $10 \mathrm{mM}$ HEPES, $1.0 \mathrm{mM}$ sodium pyruvate, $10 \%$ fetal bovine serum, 100 units $/ \mathrm{mL}$ penicillin, and $100 \mu \mathrm{g} / \mathrm{mL}$ streptomycin. All cell lines were maintained at $37^{\circ} \mathrm{C}$ in an atmosphere of $5 \% \mathrm{CO}_{2}$ and $95 \%$ air and $95 \%$ humidity.

\section{Cytotoxic activity of tumor cells}

The cytotoxic activity of tumor cells was evaluated by the 3-(4,5-dimethylthiazol-2yl)-2,5-diphenyl tetrazolium bromide (MTT) method (13). Briefly, tumor cells cultured in appropriate flasks and maintained in continuous exponential growth were detached with $0.05 \%$ trypsin, $0.02 \%$ EDTA in calcium-free phosphate-buffered saline and washed three times with RPMI medium at $1000 \mathrm{rpm} / 15 \mathrm{~min}$ at $10^{\circ} \mathrm{C}$. Cells were placed on 96-well plates at a density of $1 \times 10^{5}$ cells per well. After $24 \mathrm{~h}$ of culture, the medium was removed and fresh medium, with or without different concentrations of the indicated extracts/compounds/or the control drug methotrexate $(10-0.01 \mathrm{mg} / \mathrm{mL})$, was added to the wells and incubated for $24 \mathrm{~h}$. At the end of treatment, $10 \mu \mathrm{L}$ MTT $(10 \mathrm{mg} / \mathrm{mL})$ was added to the wells, and cells were incubated for a further 4 h. Finally, $50 \mu \mathrm{L} 20 \%$ sodium dodecyl sulfate solution was added to each well. Formazan crystals were dissolved at $37^{\circ} \mathrm{C}$ overnight. The absorbance of each well was read on a microplate reader at $540 \mathrm{~nm}$. The cytotoxic rate was calculated as follows: \% cytotoxicity of compounds $=1$ absorbance drug treated/absorbance control $\mathrm{x} 100$. 


\section{Trypanocidal assay}

Crude extracts and their subfractions were tested in vitro against trypomastigote blood forms of T. cruzi (Y strain). The bioassays were carried out using blood collected from Swiss albino mice by cardiac puncture during the parasitemic peak (7th day) after infection with the $\mathrm{Y}$ strain of $T$. cruzi. The blood was diluted in non-infected murine blood to give a concentration of ca. $2 \times 10^{6}$ trypomastigote forms $/ \mathrm{mL}$. Stock solutions of the extracts and fractions to be tested were prepared by dissolving dimethyl sulfoxide to a final concentration of $25 \mathrm{mg} / \mathrm{mL}$. The bioassays were performed in triplicate on 96-well microtiter plates containing $200 \mu \mathrm{L}$ of mixture/well. For each sample, aliquots of the stock solutions were added to the diluted blood in such quantities as to give final concentrations of 100, 250 and $500 \mu \mathrm{g} /$ $\mathrm{mL}$ sample per $\mathrm{mL}$ of mixture in the wells. The plates were incubated at $4^{\circ} \mathrm{C}$ for $24 \mathrm{~h}$ and the number of parasites was determined (14). Blood of infected mice and infected blood with dimethyl sulfoxide added in amounts equivalent to the samples were used as control, and infected blood plus gentian violet $(250 \mu \mathrm{g} / \mathrm{mL})$ was used as positive control.

\section{Results and Discussion}

Pentacyclic lupane- and ursane-like triterpene skeletons were detected in A. amazonicus stem crude extracts and fractions. Some of them were previously reported in root extracts of the same species (1).

Bioassay-guided fractionation of the EtOAc $\left(\mathrm{E}_{2}\right)$ and $\mathrm{MeOH}\left(\mathrm{E}_{6}\right)$ extracts using a combination of column chromatography, PTLC and HPLC led to the isolation of ursolic acid (1), betulinic acid (2), lupenone (3), betulin (4), 33-hydroxylup-20(29)-ene27,28-dioic acid (5), and 2 $\alpha, 3 \beta$-dihydroxylup-20(29)-ene-27,28-dioic acid (6) (Figure $1)$, as well as the well-known phytosteroids stigmasterol, sitosterol and campesterol. Compounds 2 and 4 have been isolated from A. amazonicus root bark extract (1) whereas the others are reported here for the first time for this species. Compounds 5 and 6 are
Figure 1. Structures of pentacyclic triterpenes. Ursolic acid (1), betulinic acid (2), lupenone (3), betulin (4), 3Bhydroxylup-20(29)-ene-27,28dioic acid (5), and $2 \alpha, 3 \beta$ dihydroxylup-20(29)-ene-27,28dioic acid (6).

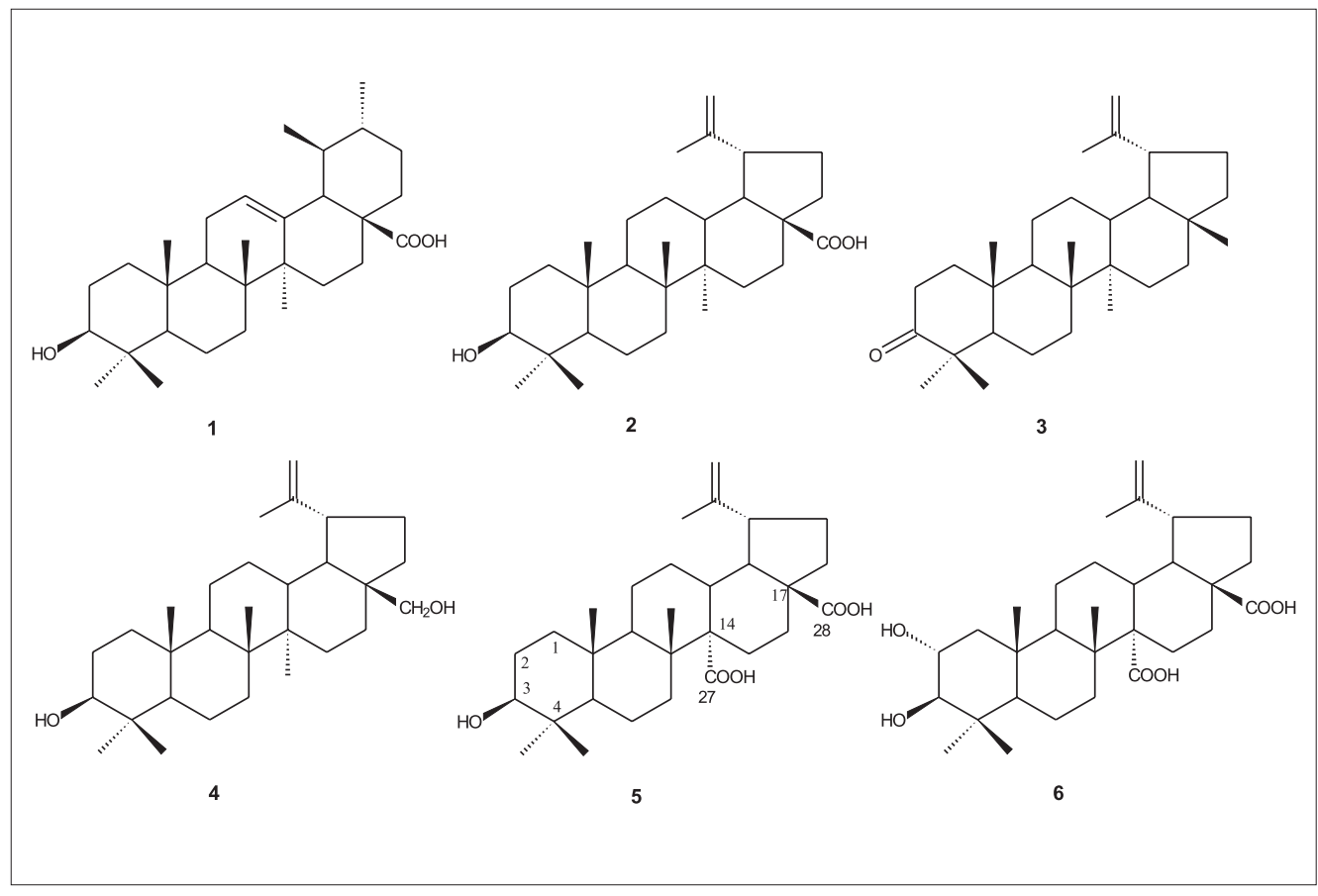


correlated, at least in part, to the cytotoxic activity of the extract.

The structures of the isolated compounds were determined using spectroscopic methods (MS, ${ }^{1} \mathrm{H}$ and ${ }^{13} \mathrm{C}$ NMR, DEPT, COSY, and $\mathrm{HMQC}$ ) in comparison with previously published data (1,15-19). Both 1-D and 2-D NMR experiments $\left({ }^{1} \mathrm{H},{ }^{13} \mathrm{C}\right.$, DEPT, ${ }^{1} \mathrm{H}-{ }^{1} \mathrm{H}$ COSY, and HMQC) were performed in order to fully assign ${ }^{1} \mathrm{H}$ and ${ }^{13} \mathrm{C}$ chemical shifts to compounds $1-6$. The ${ }^{13} \mathrm{C}$ NMR spectra of compounds 1-6 revealed 30 carbon signals whose multiplicities were sorted by DEPT spectrum (Table 1).

The $\Delta^{20,29}$-functionality of a lupane skeleton was inferred for compounds 2-6 from the resonance of the $\mathrm{sp}^{2}$ carbons at $\mathrm{C}-29$ (secondary carbon signal deduced by DEPT pulse sequence) at $110 \mathrm{ppm}$ and C-20 (quaternary carbon) at $151 \mathrm{ppm}$.

A detailed analysis of the ${ }^{1} \mathrm{H}$ NMR of 26 confirmed the characteristic features of a lupane parent structure, with some modifications. The spectra of 5 and 6 were characterized by signals of four tertiary methyls $(\delta$ 0.8-1.2, Me-23-Me-26) and one vinylic meth$\mathrm{yl}(\delta 1.9, \mathrm{Me}-30)$, two protons of an isopropenyl moiety at $\delta 4.7$ and $5.0(1 \mathrm{H}$ each, s, $\mathrm{H}_{\mathrm{a}}-29$ and $\left.\mathrm{H}_{\mathrm{b}}-29\right)$, and one carbinolic proton for 5 and two carbinolic protons for 6 . The ${ }^{1} \mathrm{H}$ NMR spectrum of 5 showed a signal at $\delta$ 3.2 (dd with $J=10.5$ and $5.3 \mathrm{~Hz}$ ) due to coupling with two methylene protons. The values of the chemical shift and $J$ couplings (diaxial and axial/equatorial interactions) suggested the presence of $\mathrm{B}-\mathrm{OH}$ substitutions at C-3 (15).

The ${ }^{1} \mathrm{H}$ NMR spectrum of 6 showed a signal for a carbinyl proton at $\delta 3.2$ (d with $J$ $=9.0 \mathrm{~Hz}$ ) due to coupling with one proton, a diaxial interaction. A signal at $\delta 4.0(1 \mathrm{H}$, ddd) was also present in the same region of the ${ }^{1} \mathrm{H}$ NMR spectrum of 6 . The COSY spectrum showed the correlation between $\mathrm{H}-2$ and H-3. The chemical shifts and $J$ couplings were typical for a $2 \alpha, 3 \beta$-dihydroxy substitution pattern (16).
The ${ }^{13} \mathrm{C}$ NMR spectrum of compound 5 revealed 30 carbon signals. The signals of 5 were sorted by DEPT spectrum as 5 methyls, 10 methylenes, 5 methines, 5 quaternaries, 1 alcoholic methine, 2 carboxylic acids, and 2 olefinic carbons $\left(1=\mathrm{CH}_{2}\right.$ and one quaternary). The signals of 6 were similar to those of 5, except for the substitution of one proton of methylene carbon with $1 \mathrm{OH}$.

The substitution at $\mathrm{C}-14$ was revealed by a shift of the carbon signal at carboxylic group at $\delta 42.8$ of betulinic acid to $\delta 60.0$ and by the deshielded of signals of C-7, C-9, C12, C-13, C-16 and C-26, and by the shielded

Table $1 .{ }^{13} \mathrm{C}$ NMR chemical shifts of pentacyclic triterpenes 1-6 (pyridine- $d_{5}$ ) with tetramethylsilane as internal standard.

\begin{tabular}{|c|c|c|c|c|c|c|}
\hline \multirow[t]{2}{*}{ Carbon } & \multicolumn{6}{|c|}{ Pentacyclic triterpenes } \\
\hline & 1 & 2 & 3 & 4 & 5 & 6 \\
\hline 1 & 38.9 & 39.1 & 39.6 & 39.4 & 39.2 & 48.0 \\
\hline 2 & 27.9 & 28.1 & 34.1 & 28.1 & 28.0 & 68.7 \\
\hline 3 & 78.0 & 78.0 & 216.4 & 77.9 & 77.7 & 83.3 \\
\hline 4 & 39.2 & 39.3 & 47.6 & 39.1 & 39.1 & 39.6 \\
\hline 5 & 55.7 & 55.7 & 54.8 & 55.7 & 55.8 & 55.9 \\
\hline 6 & 18.6 & 18.6 & 19.7 & 18.6 & 18.6 & 18.7 \\
\hline 7 & 33.4 & 34.7 & 33.8 & 34.7 & 35.2 & 35.5 \\
\hline 8 & 39.8 & 40.9 & 40.8 & 41.1 & 40.6 & 40.6 \\
\hline 9 & 47.9 & 50.8 & 49.9 & 50.6 & 51.5 & 51.1 \\
\hline 10 & 37.3 & 37.3 & 36.9 & 37.4 & 37.5 & 38.8 \\
\hline 11 & 23.5 & 21.0 & 21.5 & 20.9 & 21.1 & 21.3 \\
\hline 12 & 125.5 & 25.9 & 25.9 & 25.6 & 26.7 & 26.8 \\
\hline 13 & 139.1 & 38.4 & 38.5 & 37.3 & 40.1 & 40.0 \\
\hline 14 & 42.3 & 42.7 & 42.7 & 42.8 & 59.8 & 60.0 \\
\hline 15 & 28.5 & 30.1 & 27.4 & 27.4 & 28.5 & 28.6 \\
\hline 16 & 24.8 & 32.7 & 34.1 & 30.2 & 38.2 & 38.0 \\
\hline 17 & 47.9 & 56.4 & 42.7 & 48.2 & 56.4 & 56.6 \\
\hline 18 & 53.4 & 47.6 & 47.1 & 48.4 & 52.2 & 52.3 \\
\hline 19 & 39.2 & 49.6 & 47.1 & 49.0 & 47.6 & 47.7 \\
\hline 20 & 39.3 & 151.1 & 151.1 & 151.1 & 150.9 & 151.3 \\
\hline 21 & 30.9 & 31.0 & 30.1 & 29.9 & 30.9 & 31.0 \\
\hline 22 & 37.1 & 37.4 & 36.9 & 34.5 & 37.6 & 37.7 \\
\hline 23 & 28.7 & 28.5 & 26.6 & 28.5 & 28.3 & 28.8 \\
\hline 24 & 16.4 & 16.2 & 21.0 & 16.0 & 16.8 & 17.4 \\
\hline 25 & 15.5 & 16.2 & 15.8 & 16.3 & 16.2 & 17.4 \\
\hline 26 & 17.3 & 19.3 & 15.9 & 16.2 & 17.3 & 18.0 \\
\hline 27 & 23.8 & 14.7 & 14.6 & 14.8 & 178.3 & 179.0 \\
\hline 28 & 179.7 & 178.7 & 17.3 & 59.3 & 179.3 & 180.1 \\
\hline 29 & 17.4 & 109.8 & 109.8 & 109.8 & 110.1 & 109.9 \\
\hline 30 & 21.3 & 19.3 & 19.3 & 19.1 & 19.1 & 19.1 \\
\hline
\end{tabular}

1 = ursolic acid; 2 = betulinic acid; $3=$ lupenone; 4 = betulin; $5=3$ B-hydroxylup-20(29)ene-27,28-dioic acid; $6=2 \alpha, 33$-dihydroxylup-20(29)-ene-27,28-dioic acid. 
of signals of C-8 and C-15 due to $\delta$ and $\gamma$ steric effects of this substitute.

Other triterpenoids isolated from this plant were identified as ursolic acid (1), betulinic acid (2), lupenone (3), and betulin (4) by their spectral data as well as by comparison with spectral data from the literature $(16,17)$. Besides these triterpenes, three phytosteroids were identified by GC/MS: sitosterol, stigmasterol and campesterol.

The cytotoxic activities of 5 and 6 were evaluated on the SKBR-3 and C-8161 human tumor cell lines. Both compounds exhibited cytotoxic activity against SKBR-3 breast adenocarcinoma tumor cells. Compound 6 , even at moderate concentrations, also showed cytotoxic activity against C8161 melanoma tumor cells (Table 2).

Previous study reported that A. amazonicus stem extracts are sources of pentacyclic triterpenes that exhibit selective cytotoxicity against several melanoma-derived cell lines (20). It has been recently reported that betulinic acid is cytotoxic against non-melanoma (neuroectodermal and malignant brain tumor) human tumor varieties (21).

The present results support previous data showing that compounds found in A. amazonicus extracts exhibit tumor cytotoxicity. We also suggest that the compounds 5 and 6 isolated from A. amazonicus stem extracts and described here play a role in the tumor cytotoxicity exhibited by such extracts. In particular, the present results show that compound 5 has selective cytotoxicity against breast adenocarcinoma tumor cells and that compound 6 displays cytotoxic activity against both tumor cell lines assayed at the tested concentration. Compounds 5 and 6 did not show significant cytotoxic activity on peripheral blood mononuclear cells (data not shown). This observation agrees with data showing that lupane-type triterpenes such as betulinic acid present specific cytotoxicity against tumor cells and a favorable therapeutic index even at doses up to 500 $\mathrm{mg} / \mathrm{kg}$ body weight. Betulinic acid is a very promising new chemotherapeutic agent for the treatment of cancer (20-23). The mechanisms of triterpene cytotoxic activity on tumor cells have not been fully elucidated. Betulinic acid seems to function by inducing apoptosis of cells irrespective of their p53 status (21). Further experiments are necessary to check the apoptosis-inducing ability of compounds 5 and 6 . The activity of extracts and pure compounds seems to be much lower than established by the criteria of the American National Cancer Institute. However, activity should not be judged by direct comparison of numerical values because the cell lines and the bioassay experimental con-

Table 2. Characterization of the in vitro cytotoxicity-related anti-tumor effects of the crude extract of Ampelozizyphus amazonicus stem bark and of compounds 5 and 6.

\begin{tabular}{|c|c|c|c|c|c|c|}
\hline \multirow[t]{3}{*}{ Compounds } & \multicolumn{6}{|c|}{ \% Cytotoxicity } \\
\hline & \multicolumn{3}{|c|}{ SKBR-3 human adenocarcinoma cell lines } & \multicolumn{3}{|c|}{ C-8161 human melanoma cell lines } \\
\hline & $0.1 \mathrm{mg} / \mathrm{mL}$ & $1 \mathrm{mg} / \mathrm{mL}$ & $10 \mathrm{mg} / \mathrm{mL}$ & $0.1 \mathrm{mg} / \mathrm{mL}$ & $1 \mathrm{mg} / \mathrm{mL}$ & $10 \mathrm{mg} / \mathrm{mL}$ \\
\hline$E_{2}$ extract & $30.5 \pm 1.8$ & $44.3 \pm 2.2$ & $53.3 \pm 0.9$ & $1.3 \pm 0.5$ & $45.5 \pm 1.7$ & $76.3 \pm 2.1$ \\
\hline 5 & 0.0 & $39.4 \pm 1.9$ & $45.6 \pm 2.5$ & 0.0 & 0.0 & $14.3 \pm 0.4$ \\
\hline 6 & $30.6 \pm 2.7$ & $32.5 \pm 1.0$ & $42.5 \pm 3.1$ & $14.3 \pm 1.7$ & $35.5 \pm 2.3$ & $68.1 \pm 3.2$ \\
\hline Methotrexate & $3.5 \pm 0.2$ & $10.8 \pm 1.1$ & $36.8 \pm 3.6$ & $1.66 \pm 0.7$ & $10.5 \pm 0.8$ & $63.7 \pm 2.4$ \\
\hline
\end{tabular}

Data are reported as the means \pm SD of triplicate samples and are representative of at least three independent experiments. The cytotoxic activity of the extract or isolated compounds was analyzed by the 3(4,5-dimethylthiazol-2-yl)-2,5-diphenyl tetrazolium bromide assay as described in Material and Methods. Methotrexate was used as positive control. 
ditions, and probably the criteria for the judgment of activity used by different laboratories might not be the same.

The trypanocidal activity of crude extracts and fractions of A. amazonicus is shown in Table 3. The results demonstrated that all samples tested were effective against the $\mathrm{Y}$ strain of $T$. cruzi; however, the $\mathrm{E}_{9}$ and EEBAa extracts and fractions $\mathrm{E}_{2} \mathrm{P}, \mathrm{E}_{2} \mathrm{P}_{3}, \mathrm{E}_{2} \mathrm{P}_{9}$, and $\mathrm{E}_{7(5 / 6)}$ were more efficient and exhibited more than $50 \%$ parasite lysis at a concentration of $500 \mu \mathrm{g} / \mathrm{mL}$. Though the other extracts and fractions were less effective they presented active compounds. Fraction $\mathrm{E}_{2} \mathrm{P}$ showed activity mainly due to compounds 2,5 and 6 . After chromatographic purification, two fractions, $\mathrm{E}_{2} \mathrm{P}_{3}$ and $\mathrm{E}_{2} \mathrm{P}_{9}$, were obtained, containing compounds 5 and 6 , respectively. Fraction $\mathrm{E}_{7(5 / 6)}$, obtained by $n$-butanol partition of $E_{7}$, contains lupenone (3) and betulin (4).

The lupane- and ursane-like skeletons of pentacyclic triterpenes were identified in the extracts and fractions, as well as in the roots of A. amazonicus (1). Ursolic and oleanolic acids and their derivatives showed trypanocidal activity, with ursolic acid being the most active (24). The presence of a free hydroxyl group at $\mathrm{C}-3$ and/or the carboxyl group at C-17 is required for trypanocidal activity (24). The
Table 3. Percent parasite lysis induced by extracts and fractions of Ampelozizyphus amazonicus against the trypomastigote form of Trypanosoma cruzi $Y$ strain.

\begin{tabular}{lrcc}
\hline Extracts and fractions & \multicolumn{3}{c}{ Concentration $(\mu \mathrm{g} / \mathrm{mL})$} \\
\cline { 2 - 4 } & \multicolumn{1}{c}{100} & 250 & 500 \\
\hline$E_{1}$ & $4.86 \pm 0.87$ & $19.63 \pm 7.44$ & $25.16 \pm 4.61$ \\
$E_{2}$ & $33.73 \pm 0.00$ & $34.97 \pm 0.89$ & $42.94 \pm 1.51$ \\
$E_{3}$ & $5.53 \pm 1.74$ & $17.20 \pm 4.49$ & $32.53 \pm 6.24$ \\
$E_{4}$ & $17.2 \pm 4.49$ & $17.2 \pm 3.96$ & $46.03 \pm 3.48$ \\
$E_{5}$ & $11.06 \pm 5.28$ & $17.16 \pm 1.51$ & $25.77 \pm 5.66$ \\
$E_{6}$ & $19.63 \pm 4.84$ & $23.93 \pm 1.74$ & $23.93 \pm 2.28$ \\
$E_{7}$ & $19.03 \pm 6.00$ & $22.70 \pm 4.49$ & $39.86 \pm 1.74$ \\
$E_{8}$ & $8.60 \pm 3.78$ & $20.23 \pm 1.74$ & $30.06 \pm 9.02$ \\
$E_{9}$ & $2.80 \pm 2.37$ & $17.26 \pm 3.94$ & $66.50 \pm 5.93$ \\
$E_{10}$ & $11.16 \pm 7.99$ & $30.80 \pm 0.00$ & $43.46 \pm 5.10$ \\
$E_{2} P$ & $38.20 \pm 5.39$ & $55.00 \pm 5.31$ & $82.00 \pm 5.58$ \\
$E_{2} P_{3}$ & $26.70 \pm 7.85$ & $46.06 \pm 2.64$ & $57.06 \pm 5.36$ \\
$E_{2} P_{9}$ & $12.56 \pm 5.15$ & $49.70 \pm 0.00$ & $53.43 \pm 7.71$ \\
$E_{7(5 / 6)}$ & $61.33 \pm 6.52$ & $60.73 \pm 1.26$ & $62.36 \pm 5.22$ \\
$E_{B B A}$ & $59.53 \pm 7.59$ & $62.30 \pm 8.90$ & $61.26 \pm 1.46$
\end{tabular}

Data are reported as the means \pm SD of triplicate samples and are representative of at least three independent experiments. Positive control: gentian violet (100\% lysis). The entire extraction and purification processes are described in Material and Methods.

results obtained demonstrate that $A$. amazonicus extracts contain potential compounds for use as chemoprophylactic agents against $T$. cruzi. In addition, triterpenes, compounds such as phenols, saponins, peptide alkaloids, and others have been identified in Rhamnaceae species $(5,25-28)$.

\section{References}

1. Brandao MG, Lacaille-Dubois MA, Teixera MA, Wagner H. Triterpene saponins from the roots of Ampelozizyphus amazonicus. Phytochemistry 1992; 31: 352-354.

2. Krettli AU, Andrade-Neto VF, Brandao MG, Ferrari WM. The search for new antimalarial drugs from plants used to treat fever and malaria or plants randomly selected: a review. Mem Inst Oswaldo Cruz 2001; 96: 1033-1042.

3. Brandao MG, Lacaille-Dubois MA, Teixeira MA, Wagner H. A dammarane-type saponin from the roots of Ampelozizyphus amazonicus. Phytochemistry 1993; 34: 1123-1127.

4. Popoca J, Aguilar A, Alonso D, Villarreal ML. Cytotoxic activity of selected plants used as antitumorals in Mexican traditional medicine. J Ethnopharmacol 1998; 59: 173-177.

5. Suksamrarn S, Panseeta P, Kunchanawatta S, Distaporn T, Ruktasing S, Suksamrarn A. Ceanothane- and lupane-type triterpenes with antiplasmodial and antimycobacterial activities from Ziziphus cambodiana. Chem Pharm Bull 2006; 54: 535-537.
6. Velazco MR, Montero R, Rojas E, Gonsebatt ME, Sordo M, Pineyro A, et al. Genotoxic effects of Karwinskia humboldtiana toxin T-514 in peripheral blood lymphocytes. Anticancer Drugs 1996; 7: 710-715.

7. Lin CC, Chang CH, Yang JJ, Namba T, Hattori M. Hepatoprotective effects of emodin from Ventilago leiocarpa. J Ethnopharmacol 1996; 52: 107-111.

8. Chang $\mathrm{CH}$, Lin CC, Yang JJ, Namba T, Hattori M. Anti-inflammatory effects of emodin from Ventilago leiocarpa. Am J Chin Med 1996; 24: 139-142.

9. Docampo R, Moreno SN, Gadelha FR, de Souza W, Cruz FS. Prevention of Chagas' disease resulting from blood transfusion by treatment of blood: toxicity and mode of action of gentian violet. Biomed Environ Sci 1988; 1: 406-413.

10. Sepulveda-Boza S, Cassels BK. Plant metabolites active against Trypanosoma cruzi. Planta Med 1996; 62: 98-105.

11. Rassi A, Amato Neto V, de Siqueira AF, Ferriolli FF, Amato VS, Rassi GG, et al. Treatment of chronic Chagas' disease with an 
association of nifurtimox and corticoid. Rev Soc Bras Med Trop 2002; 35: 547-550.

12. Lauria-Pires L, Braga MS, Vexenat AC, Nitz N, Simoes-Barbosa A, Tinoco DL, et al. Progressive chronic Chagas heart disease ten years after treatment with anti-Trypanosoma cruzi nitroderivatives. Am J Trop Med Hyg 2000; 63: 111-118.

13. Mosmann T. Rapid colorimetric assay for cellular growth and survival: application to proliferation and cytotoxicity assays. $J$ Immunol Methods 1983; 65: 55-63.

14. Brener Z. Therapeutic activity and criterion of cure on mice experimentally infected with Trypanosoma cruzi. Rev Inst Med Trop São Paulo 1962; 4: 389-396.

15. Bilia AR, Morelli I, Mendez J. New lupane derivatives from the leaves of Licania pyrifolia. J Nat Prod 1996; 59: 297-300.

16. Mahato SB, Kundu AP. ${ }^{13} \mathrm{C}$ NMR spectra of pentacyclic triterpenoids - A compilation and some salient features. Phytochemistry 1994; 37: 1517-1575.

17. Dantanarayana AP, Kumar NS, Muthukuda PM, Mohamed I, Wazeer M. A lupane derivative and the ${ }^{13} \mathrm{C}$ NMR chemical shifts of some lupanols from Pleurostylia opposita. Phytochemistry 1982; 21: 20652068.

18. Kiem PV, Dat NT, Minh CV, Lee JJ, Kim YH. Lupane-triterpenes from the leaves of Brassaiopsis glomerulata. Arch Pharm Res 2003; 26: 594-596.

19. Plaza A, Cinco M, Tubaro A, Pizza C, Piacente S. New triterpene glycosides from the stems of Anomospermum grandifolium. J Nat Prod 2003; 66: 1606-1610.

20. Cichewicz RH, Kouzi SA. Chemistry, biological activity, and chemo- therapeutic potential of betulinic acid for the prevention and treatment of cancer and HIV infection. Med Res Rev 2004; 24: 90-114.

21. Zuco V, Supino R, Righetti SC, Cleris L, Marchesi E, GambacortiPasserini C, et al. Selective cytotoxicity of betulinic acid on tumor cell lines, but not on normal cells. Cancer Lett 2002; 175: 17-25.

22. Mukherjee R, Kumar V, Srivastava SK, Agarwal SK, Burman AC. Betulinic acid derivatives as anticancer agents: structure activity relationship. Anticancer Agents Med Chem 2006; 6: 271-279.

23. Yogeeswari $P$, Sriram D. Betulinic acid and its derivatives: a review on their biological properties. Curr Med Chem 2005; 12: 657-666.

24. Cunha WR, Martins C, da Silva FD, Crotti AE, Lopes NP, Albuquerque S. In vitro trypanocidal activity of triterpenes from miconia species. Planta Med 2003; 69: 470-472.

25. Yoshikawa M, Murakami T, Ueda T, Matsuda H, Yamahara J, Murakami N. Bioactive saponins and glycosides. IV. Four methylmigrated 16,17-seco-dammarane triterpene glycosides from Chinese natural medicine, hoveniae semen seu fructus, the seeds and fruit of Hovenia dulcis THUNB.: absolute stereostructures and inhibitory activity on histamine release of hovenidulciosides A1, A2, B1, and B2. Chem Pharm Bull 1996; 44: 1736-1743.

26. Auvin C, Lezenven F, Blond A, Augeven-Bour I, Pousset JL, Bodo $\mathrm{B}$, et al. Mucronine $\mathrm{J}$ a 14-membered cyclopeptide alkaloid from Zizyphus mucronata. J Nat Prod 1996; 59: 676-678.

27. Suttisri R, Lee IS, Kinghorn AD. Plant-derived triterpenoid sweetness inhibitors. J Ethnopharmacol 1995; 47: 9-26.

28. Li G, Min BS, Zheng C, Lee J, Oh SR, Ahn KS, et al. Neuroprotective and free radical scavenging activities of phenolic compounds from Hovenia dulcis. Arch Pharm Res 2005; 28: 804-809. 